K A N D A I

\begin{tabular}{|l|l|l|}
\hline Volume 15 & No. 1, Mei 2019 & Halaman 101-116 \\
\hline
\end{tabular}

\title{
STRATEGI PENARASIAN DAN PEMOSISIAN SUBJEK PEREMPUAN \\ DALAM MEREKA BILANG, SAYA MONYET! \\ KARYA DJENAR MAESA AYU: PERSPEKTIF POSFEMINISME \\ (Narration Strategic and Woman's Positioning as Subject on Mereka Bilang, Saya Monyet! Karya Djenar Maesa Ayu: Postfeminism's Perspective)
}

\author{
Ahmad Zamzuri \\ Balai Bahasa Daerah Istimewa Yogyakarta \\ Jalan I Dewa Nyoman Oka 34 Yogyakarta, Indonesia \\ Pos-el: alakazam80@gmail.com
}

(Diterima 24 Januari 2019; Direvisi 30 April 2019; Disetujui 6 Mei 2019)

\begin{abstract}
This study discusses six short stories in the anthology of Djenar Maesa Ayu's work entitled Mereka Bilang, Saya Monyet! through a post feminism perspective. The problem in this study relates to the narration of women as victims in the patriarchal space. The aim of the study was to reveal the narration of women, the position of female subjects, and the discourse embedded in the short stories. To achieve the goal, this research was conducted in several stages, such as choosing object of research and the theoretical framework, collecting data, analysis, and conclusions. The object of this study consist of six short stories by Djenar Maesa Ayu, including "Mereka Bilang, Saya Monyet! "Lintah", "Durian", "Melukis Jendela", "Wong Asu", and "Namanya ....". Data is collected through in-depth reading and quoting words, phrases, sentences, paragraphs, and dialogues which are then described analytically. The data is then analyzed by interpreting all linguistic tools and connecting them with the postfeminism perspective. The results showed that women were narrated as if they were objects in the space of patriarchal domination, but instead they became a central subject who carried out resistance to patriarchal discourse by giving calls in the form of names of animal heads according to the nature and behavior of men, including Si Kepala Gajah, Si Kepala Sapi, dan Si Kepala Anjing. Other resistance carried out by women, through slashing the cheek and cutting penis, the symbol of man's power. The narration in the short story of Djenar Maesa Ayu's works shows satire that men is not smarter than women whose called monkeys by them.
\end{abstract}

Keywords: discourse, subject, woman, resistance, postfeminism.

\begin{abstract}
Abstrak
Penelitian ini membahas enam cerita pendek dalam antologi karya Djenar Maesa Ayu yang berjudul Mereka Bilang, Saya Monyet! melalui perspektif postfeminisme. Masalah dalam penelitian ini berkaitan dengan narasi perempuan sebagai korban dalam ruang patriarki. Tujuan dari penelitian ini adalah untuk mengungkapkan narasi perempuan, posisi subyek perempuan, dan wacana yang tertanam dalam cerita pendek. Untuk mencapai tujuan tersebut, penelitian ini dilakukan dalam beberapa tahap, seperti memilih objek penelitian dan kerangka teori, pengumpulan data, analisis, dan kesimpulan. Objek penelitian terdiri atas enam cerita pendek oleh Djenar Maesa Ayu, termasuk "Mereka Bilang, Saya Monyet!", "Lintah", "Durian", "Melukis Jendela", "Wong Asu", dan "Namanya ....". Data dikumpulkan melalui pembacaan mendalam dan mengutip kata-kata, frasa, kalimat, paragraf, dan dialog yang kemudian dideskripsikan secara analitis. Data tersebut kemudian dianalisis dengan menginterpretasikan semua alat linguistik dan menghubungkannya dengan perspektif posemineminisme. Hasil penelitian menunjukkan bahwa perempuan dinarasikan seolah-olah mereka adalah objek dalam ruang dominasi patriarkal, tetapi sebaliknya menjadi subjek utama yang melakukan perlawanan terhadap wacana patriarki dengan memberikan panggilan dalam bentuk nama-nama kepala hewan sesuai dengan sifat dan perilaku pria,
\end{abstract}


termasuk Si Kepala Gajah, Si Kepala Sapi, dan Si Kepala Anjing. Perlawanan lain yang dilakukan oleh perempuan, yaitu menyayat pipi dan memotong penis, simbol kekuatan lakilaki. Narasi dalam cerita pendek karya Djenar Maesa Ayu menampilkan sindiran kepada laki-laki sebagai orang yang tidak lebih pintar dari wanita yang disebutnya monyet.

Kata-kata kunci: wacana, subjek, perempuan, resistansi, posfeminisme

DOI: $10.26499 / j k . v 15 i 1.1262$

How to cite: Zamzuri, A.(2019). Strategi penarasian dan pemosisian subjek perempuan dalam Mereka Bilang, Saya Monyet! karya Djenar Maesa Ayu: Perspektif posfeminisme. Kandai, 15(1), 101-116 (DOI:10.26499/jk.v15i1.1262)

\section{PENDAHULUAN}

Dalam jagat kesusastraan Indonesia, Djenar Maesa Ayu luas dikenal dengan karya yang menggunakan gaya bahasa yang lugas, bahkan vulgar, sehingga seakan mengumbar seksualitas melalui pemilihan kosakata yang berelasi langsung dengan organ seksual laki-laki, perempuan, dan seksualitas. Meskipun dianggap vulgar melalui konteks bahasa yang digunakan, salah satu karya Djenar Maesa Ayu yang terangkum dalam antologi cerita pendek Mereka Bilang, Saya Monyet!, terbit pada September 2002, mengalami cetak ulang sebanyak 10 kali hingga tahun 2012. Tetapi, yang menarik bukan pada berulang-ulangnya terbit, melainkan pada wacana yang dihadirkan melalui karya tersebut, yaitu mengenai "pemberontakan" terhadap wacana mapan yang didominasi oleh laki-laki. Seksualitas tidak lagi hadir secara metaforis, atau samar-samar, melain-kan langsung dan berani berseberangan dengan konsep tabu yang lama diamini masyarakat dalam konteks budaya dan norma ketimuran. Kehadiran Mereka Bilang, Saya Monyet!, khususnya, menjadi semacam counter stereotype terhadap anggapan bahwa perempuan selalu ditentukan oleh budaya partiarki.

Cerita pendek Mereka Bilang, Saya Monyet! pada mulanya adalah cerita pendek karya Djenar Maesa Ayu yang terbit di Jurnal Cerpen Indonesia, 1 Februari 2002, yang kemudian menjadi judul antologi cerita pendeknya.
Munculnya antologi cerita pendek Mereka Bilang, Saya Monyet! menjadi tonggak bagi Djenar Maesa Ayu untuk menapaki dunia menulis dengan karyakarya yang melawan arus konvensi normatif penulisan karya sastra di Indonesia. Di kemudian hari, gaya penarasian tersebut melambungkan nama Djenar Maesa Ayu sebagai salah satu perempuan penulis di jagad sastra Indonesia.

Tidak sedikit kritikus sastra yang menganggap karya-karya Djenar Maesa Ayu membawa warna baru dalam khazanah sastra Indoensia. Djenar Maesa Ayu menjadi bagian dari mode "tulisan berbau seks" yang sedang melanda Indonesia (Bandel, 2006). Dikatakan bagian dari mode, setidaknya bahwa sebelumnya, Ayu Utami telah menghadirkan terlebih dahulu Saman (2001) dan Larung (2002), dan kemudian Djenar Maesa Ayu meluncurkan Mereka Bilang, Saya Monyet!, yang juga "berbau seks". Tidak dimungkiri bahwa fenomena seks yang digambarkan dalam karya sastra (prosa) Indonesia mutakhir didominasi oleh fenomena hubungan seks di luar nikah, homoseksual, perselingkuhan, hubungan seks dengan pelacur, hubungan suami istri, dan inses (Wiyatmi, 2006).

Meskipun demikian, bagi Sutardji Colzoum Bachri, Mereka Bilang, Saya Monyet! tidak sekadar memasalahkan perilaku seks, melainkan menghadirkan trauma masa kecil, hubungan seorang gadis yang problematis dengan orang tua beserta pelecehan seksual terhadap sang anak, moralitas, dan gender 
(perselingkuhan), serta respon atau akibat bagi para korban dengan bahasa yang kuat dan padat sehingga terkesan tidak menyia-nyiakan kata-kata beserta mak-nanya (Ayu, 2012).

Sebagai perbandingan, misalnya, kosakata dalam novel Perempuan Berkalung Sorban karya Abidah El Khalieqy, yang cenderung metaforis dan sama-sama menggambarkan resistansi terhadap wacana patriarki (Wildan, 2014), memiliki perbedaan dalam hal pilihan kosakata dengan cerpen-cerpen dalam Mereka Bilang, Saya Monyet! yang tergolong "menohok", khususnya mengenai organ vital laki-laki dan perempuan, dan aktivitas seks. Kisahkisah dalam Mereka Bilang, Saya Monyet! cenderung mengisahkan perempuan sebagai korban dan tersubjeksi oleh laki-laki. Anggapan tersebut sealur dengan kajian berjudul "Representasi Kekerasan Seksual Terhadap Perempuan dalam Kumpulan Cerpen Mereka Bilang Saya Monyet Karya Djenar Maesa Ayu (Pendekatan Kritik Sastra Feminis Psikoanalisis)" (Sukma, 2011). Sukma menyimpulkan tokoh-tokoh perempuan dalam empat cerpen, yaitu "Lintah", "Durian", "Melukis Jendela", dan "Namanya..", menjadi korban seksual dari orang tua dan kerabat dekat.

Dari anggapan tersebut muncul asumsi bahwa, sebagai seorang perempuan yang berprofesi sebagai penulis, apakah Djenar Maesa Ayu benar-benar menempatkan perempuan pada posisi yang tidak menguntungkan sebagai korban dominasi laki-laki. Sebagai seorang humanis, rasanya tidak mungkin bahwa Djenar Maesa Ayu benar-benar menempatkan posisi perempuan sebagai korban. Djenar Maesa Ayu, dalam sebuah kesempatan pada Pesta Film Solo 7 di Teater Arena Taman Budaya Jawa Tengah (13/5/17), mengungkapkan bahwa, meskipun semua karyanya bermuatan soal perempuan, baik dalam cerpen, novel, maupun film, semuanya itu adalah memperjuangkan kemanusiaan. Dari situlah ia lebih ingin disebut sebagai seorang humanis, ketimbang feminis (Setyowati, 15 Mei 2017).

Mempertimbangkan posisi perempuan yang cenderung sebagai korban di dalam antologi Mereka Bilang, Saya Monyet!, sejatinya menghadirkan beberapa asumsi. Pertama, hadirnya wacana yang sedang berdialektika dan mengajak pembaca untuk lebih rinci dan teliti dalam membaca kisah-kisah yang ditu-lisnya. Kedua, cerpen-cerpen dalam antologi Mereka Bilang, Saya Monyet! sedang menyodorkan wacana melalui narasi-narasi dalam antologi untuk menunjukkan sejatinya "monyet" perempuan atau laki-laki. Ketiga, Djenar Maesa Ayu sedang melakukan perlawanan simbolik melalui karya sastra, seperti para sastrawan melalui prosa (novel) Indonesia yang hadir pada 1920-1980 (Wiyatmi, 2010), terhadap wacana budaya yang didominasi oleh struktur patriarki.

Dalam lingkup wacana yang didominasi oleh laki-laki, kehadiran antologi Mereka Bilang, Saya Monyet! menjadi sebuah wacana yang menunjukkan subjek cenderung diposisikan oleh wacana/tatanan kehidupan pada posisi yang di-liyan-kan. Sebagai yang liyan dalam wacana lakilaki, Djenar Maesa Ayu tampak hadir sebagai diri sendiri dan independen dengan gaya bahasa dan lensa pandang yang cenderung berakar dari kriterianya sendiri. Djenar Maesa Ayu tampak sedang keluar dari dikotomi oposisi biner, atau dari dominasi tatanan patriarki. Dari sinilah, Djenar Maesa Ayu tampak seperti yang digagas oleh para pemikir Luce Irigaray, Helen Cixous, dan Julia Kristeva mengenai feminis postmodern yang menolak 
oposisi biner dari dominasi tatanan patriarki (Salam, 2018). Dari sinilah Djenar Maesa Ayu menunjukkan subjek yang berusaha keluar dari kerangka struktural wacana partriarki dan membangun tatanannya sendiri, yang berarti berada pada posisi postruktural, yang menolak struktur. Persinggungan antara posmodernisme, postrukturalisme, dengan feminisme inilah kemudian menghadirkan sebuah sebuah perspektif postfeminisme. Dari argumen ini kemudian hadir sebuah shestory bukan hi(s)story dengan basis penolakan terhadap monopoli diskursus yang terstruktur berdasarkan patriarki.

Dalam penelitian karya sastra yang menggunakan perspektif postfemenisme, setidaknya, telah ditemukan penelitian karya sastra berdasarkan perspektif postfeminisme, yaitu "Membaca Diskursus Post-Feminisme Melalui Novel "Perempuan di Titik Nol" (Prasetyo, 2010). Penelitian tersebut menggunakan data primer dari novel Perempuan di Titik Nol karya Nawal El Saadawi yang berjudul asli Women at Point Zero. Melalui penelitian tersebut, Prasetyo menyimpulkan bahwa cerita hidup Firdaus seolah-olah telah menelanjangi para lelaki yang selama ini terbuai oleh rezim patriarki, mengungkap ketidak-adilan dan opresi yang selama ini telah terjadi secara sistemik dan nirsadar, serta dengan berani telah mewacanakan ide-ide tentang pembebasan perempuan dari jerat-jerat struktural dan kultural kehidupan yang patriarki dan phallosentrik (berpusat pada laki-laki).

Dari uraian tersebut dan perbandingan dengan penelitian yang telah dilakukan oleh peneliti lainnya, masalah penelitian kali ini berkaitan dengan resistansi, posisi subjek perempuan, dalam antologi Mereka Bilang, Saya Monyet! Dari masalah tersebut, pertanyaan penelitiannya adalah bagaimana narasi perempuan dan bagaimana posisi subjek perempuan berdasarkan perspektif postfeminisme dalam antologi cerpen Mereka Bilang, Saya Monyet!. Tujuan penelitan ini untuk mengungkap penarasian perempuan dan posisi subjek dalam antologi cerpen Mereka Bilang, Saya Monyet!. Selain itu, penelitian ini juga bertujuan untuk mengetahui wacana yang disematkan pada penarasian perempuan dalam antologi cerpen Mereka Bilang, Saya Monyet!.

\section{LANDASAN TEORI}

Konsep postfeminisme merupakan persi-langan beberapa konsep epistemologis dari teori poststruktural dan postmodernisme, bahkan postkolonialisme. Dari persinggungan epistemologis tersebut, tidak jarang menghadirkan kerancuan pemaknaan "post" dalam posfeminisme. Ann Brooks (1997) dalam bukunya Postfeminisms: Feminism, Cultural Theory, and Cultural Forms, mengungkapkan bahwa konsep "post" menyiratkan proses transformasi dan perubahan yang berkelanjutan (Brooks, 1997). Dalam pendapatnya tersebut, postkolonial dianggap sebagai kritik terhadap kolonislisme bukan klaim untuk menjatuhkan kolonialisme. Dari pendapat tersebut, postfeminis kemudian dilabeli sebagai kritik terhadap patriarki sehingga "post" dalam posfeminis bukan suatu konsep untuk mengganti atau mengubah patriarki melainkan sebagai upaya mengkritik wacana patriarkat melalui yang dipengaruhi oleh perpektif poststrukturalis, yang berada di luar struktur mapan umumnya.

Selain melakukan kritik terhadap aliran feminis sebelumnya, postfeminisme mengeskpresikan titik temu antara feminis dan postmodern, poststrukturalis dan postkolonialisme 
yang bergerak dinamis, dan meragukan modernisme dalam kerangka patriarki dan imperialisme (Brooks, 1997). Dalam penerapannya, postfeminisme memudahkan konsep pluralistik yang diterapkan feminisme, marginalitas, diaspora, kultur negara jajahan, suara perempuan, pribumi, dan feminisme di negara bekas jajahan.

Keterlibatan feminisme dengan postmodern, bermula ketika feminisme berusaha membongkar praktik patriarki dan diskriminasi yang dilakukan modernisme terhadap wanita. Feminisme kemudian terbentur grand-narasi yang di dalamnya terdapat partriarki, Kemudian feminisme mengadopsi semangat postmodern yang berusaha meruntuhkan narasi-narasi besar dalam masyarakat. Hubungan feminisme, postmodern, dan poststrukturalisme bersifat dinamis karena feminisme telah mampu mengambil isu-isu di luar isu klasik tentang materialisme. Poststrukturalisme, khususnya dekonstruksi Derrida, psikoanalisis Lacan, dan wacana Foucault, seharusnya bisa diterapkan dalam feminisme dikarenakan post-strukturalisme menekankan pada seksualitas, subjektivitas, dan tekstualitas (Ramazanoglu, 1993).

Berkaitan pemosisian subjek, Brook menunjukkan hubungan antara feminisme dan post-strukturalisme berpusat pada subjektivitas, dikarenakan post-feminisme melakukan dekonstruksi terhadap konsep subjek. Titik temu feminisme dengan postmodernisme menghasilkan berbagai kerangka kritis, termasuk wacana, dekonstruksi, dan perbedaan (Brooks, 1997). Konsep poststruktural tersebut digunakan postfeminisme untuk melawan dan menyempurnakan asumsi-asumsi tradisional tentang identitas dan subjektivitas. Kerja postfeminisme kemudian meng-analisa bentuk diskursif kekuasaan patriarki dan bentuk-bentuk pengetahuan institusionalnya, dikarenakan laki-laki selalu mendapat legitimasi di dalam struktur kekuasaan.

Postfeminisme menawarkan subjek yang fragmentaris dan kontradiktif, dan menolak konsep hakikat perempuan yang esensial dan terpadu, kontekstualisasi pengalaman dan analisis konstitusi dan kekuatan ideologisnya (Weedon, 1993) sehingga posisi subjek postfeminis cenderung kontradiktif dan bebas melakukan pilihan wacana yang berbeda-beda dalam ruang patriarkat. Bahasa kemudian menjadi sentral pergulatan makna yang meru-pakan prasyarat untuk perubahan politik dalam kerangka pemaknaan kembali feminin (Weedon, 1993). Melalui bahasa inilah kemudian wacana-wacana yang berada di balik bahasa menjadi fokus perhatian sehingga dapat diketahui keberadaan dan pergerakan subjek yang resistansi dalam ruang patriarki.

\section{METODE PENELITIAN}

Penelitian ini dilakukan dalam beberapa tahapan. Tahap pertama, penentuan objek material dan objek formal penelitian. Objek material penelitian ini adalah antologi cerpen Mereka Bilang, Saya Monyet! yang terdiri atas sebelas cerita pendek. Selanjutnya, data dipersempit dengan memilih enam cerita pendek berjudul "Mereka Bilang, Saya Monyet!", "Lintah", "Durian", "Melukis Jendela", "Wong Asu", dan "Namanya..." sebagai data primer. Melalui data primer tersebut ditemukan permasalahan perempuan yang seakan-akan menjadi objek dalam wacana patriarki, tetapi sejatinya menunjukkan resistansi terhadap wacana patriarki.

Dari tahap penentuan objek data dan permasalahan, tahap kedua adalah pengumpulan data. Pengumpulan data dilakukan melalui beberapa tahapan, 
antara lain, yaitu membaca data primer secara seksama dan berulang untuk memperoleh pemahaman mendalam; melakukan pemetaan data dengan cara mengutip kata, frasa, kalimat, paragraf, dan dialog yang berelasi dengan subjek perempuan dan sudut pandang. Kutipankutipan tersebut kemudian dideskripsikan secara analitis.

Tahap ketiga adalah analisis data berupa kutipan-kutipan melalui analisis wacana kritis dengan menafsirkan seluruh perangkat kebahasaan dan menghubungkannya dengan kerangka postfemenisme yang cenderung mengusung semangat kebebasan menentukan posisi yang kontradiktif dengan wacana patriarki. Sementara itu, gagasan mengenai sudut pandang yang dikemukakan oleh Todorov akan digunakan untuk membantu mengungkap penarasian perempuan. Dalam konsep Todorov, setidaknya terdapat dua konsep sudut Pertama, sudut pandang objektif dan subjektif. Konsep ini berkaitan dengan kualitas informasi. Kedua, keleluasaan dan kedalaman. Keleluasaan adalah sudut pandang yang diukur berdasarkan kedalam narator menyelami tokoh hingga ke dalam pikiran. Sementara itu, kedalaman berkaitan dengan sudut pandang yang didasarkan pada upaya narator menilai pikiran dan gagasan tokoh untuk membedah kesadaran tokoh (Todorov, 1985).

Tahap keempat adalah penyimpulan hasil analisis berupa penarasian, resistansi perempuan dan peneguhan wacana perempuan dalam perspektif postfeminisme.

\section{HASIL DAN PEMBAHASAN}

Dari pembacaan data dan perelasian dengan konsep postfeminism diperoleh pemahaman bahwa penarisan perempuan dalam cerpen-cerpen antologi Mereka Bilang, Saya Monyet! menggunakan sudut pandang tertentu. Berkaitan dengan hal tersebut, pada bagian ini akan diuraikan mengenai strategi dan penarasian perempuan, dan pemosisian perempuan.

\section{Strategi dan Penarasian Perempuan}

Dalam antologi cerpen Mereka Bilang, Saya Monyet!, melalui pemilihan sudut pandang, narator memiliki kekuasaan penuh untuk menempatkan, atau mengisahkan, subjek (tokoh) sehingga pembaca turut mengikuti jejakjejak subjek dengan segala peristiwa, sekaligus alam pikirnya, yang terjadi dalam cerita.

Melalui sudut pandang orang pertama yang disematkan kepada tokoh utama "saya", narator mengarahkan pandangan dan pikiran pembaca ke arah segala hal yang dipikirkan dan dilihat oleh tokoh "saya" dalam cerita pendek. Gender perempuan melekat pada tokoh "saya", meskipun di dalam cerita pendek "Mereka Bilang, Saya Monyet!" dan tokoh "saya" tidak secara langsung disebutkan sebagai perempuan. Penyematan gender perempuan kepada tokoh "saya" tampak dalam kutipan berikut.

"Saya tahu persis siapa dirinya. Saya tahu persis Si Kepala Anjing berhubungan dengan banyak laki-laki padahal ia sudah bersuami. Saya tahu persis $\mathrm{Si}$ Kepala Anjing sering mengendus-endus kemaluan $\mathrm{Si}$ Kepala Serigala. Bahkan Si Kepala Anjing juga pernah mengendus-endus kemaluan saya walaupun kami berkelamin sama." (Ayu, 2012, hlm. 7)

Kutipan ini merupakan bagian dari cerita pendek "Mereka Bilang, Saya 
Monyet!" dan menunjukkan bahwa tokoh "saya" bergender perempuan. Tokoh "saya" bergender perempuan diketahui melalui status tokoh Si Kepala Anjing yang notabene Si Kepala Anjing telah bersuami. Kata "telah bersuami" secara implisit menunjukkan bahwa pasangan dari suami adalah istri. Dari sinilah menunjukkan bahwa Si Kepala Anjing bergender perempuan.

Sementara itu, dari tokoh "saya" mengakui bahwa Si Kepala Anjing pernah mengendus kemaluan tokoh "saya" yang senyata sama-sama bergender perempuan. Melalui tokoh "saya", selanjutnya Djenar Maesa Ayu mengisahkan dan mengonstruksi perempuan melalui sudut pandang tokoh "saya" dalam hal pemikiran dan respon terhadap ruang-ruang yang melingkupinya, termasuk melihat perempuan selain diri tokoh "saya". Dari awal hingga akhir penceritaan, tokoh "saya" dalam cerpen "Mereka Bilang, Saya Monyet!" tidak bernama.

Sudut pandang orang pertama dengan sebutan "saya" juga digunakan pada cerita pendek "Lintah". Sejak awal kisah, status gender tokoh "saya" telah dikaburkan dan tampak berusaha memosisikan tokoh "saya" pada posisi antara laki-laki dan perempuan. Identitas tokoh "saya" pada akhirnya dianggap bergender perempuan sesungguhnya tidak secara langsung disebutkan sebagai perempuan, melainkan melalui penyematan kata-kata yang memiliki relasi dengan tubuh perempuan.

“... Raga saya lumpuh. Ular itu menyergap, melucuti pakaian saya, menjalari satu per satu lekuk tubuh saya. Melumat tubuh saya yang belum berbulu dan bersusu, dan menari-nari di atasnya memuntahkan liur yang setiap tetesnya berubah menjadi lintah...." (Аyu, 2012, hlm. 16)
Kutipan tersebut menunjukkan bahwa tokoh "saya" bergender perempuan yang diketahui dari disematkannya kata "bersusu" pada diri tokoh "saya". Meskipun laki-laki secara fisik juga memiliki bagian yang identik dengan bagian susu (dada), konsep kata "bersusu" cenderung mengarah dan berelasi terhadap tubuh perempuan, yaitu bagian dada yang menonjol dan berputing yang dapat mengeluarkan air susu (ASI). Namun, pada akhir kisah tokoh "saya" dipertegas sebagai perempuan dengan nama Maha ketika ibu tokoh "saya" memanggilnya dengan sebutan Maha (Ayu, 2012). Sementara itu, dalam cerita pendek Wong Asu, sudut pandang menggunakan orang pertama dengan sebagai tokoh "saya". Akan tetapi, tokoh "saya" dalam cerita pendek Wong Asu tidak diketahui jenis gender yang melekat pada diri tokoh.

Penggunaan sudut pandang orang pertama melalui tokoh "saya" berkemungkinan besar mengetahui pemikiran tokoh "saya" mengenai diri tokoh sebagai perempuan, sekaligus pendapat diri tokoh "saya" terhadap lingkungan dan subjek-subjek yang melingkupi diri tokoh "saya". Dari sinilah kemudian, setidaknya melalui konstruksi pemikiran, perempuan hadir sebagai subjek yang berdialektika terhadap wacana dominan (patriarki) yang melingkupi tokoh perempuan.

Dalam cerita pendek "Mereka Bilang, Saya Monyet!", melalui tokoh "saya", perempuan dinarasikan sebagai makhluk yang memiliki hati dan otak, serta berwujud sebagai manusia normal, setidaknya berkaki dua dan berkepala manusia. Narasi tersebut muncul dari tokoh "saya" yang mencoba membedakan diri terhadap wacana dominasi patriarki yang melingkupi. Sementara di sisi wacana dominan (patriarki), tokoh "saya" dipandang 
sebagai makhluk bodoh dan tidak berakal (tidak berotak). Tokoh "saya" dianggap binatang, lebih spesifik sebagai monyet, oleh wacana dominan.

Sementara itu, melalui tokoh "saya" diketahui pula mengenai subjek perempuan lain yang dinarasikan sebagai $\mathrm{Si}$ Kepala Anjing. Tokoh "saya" mengisahkan bahwa Si Kepala Anjing adalah perempuan yang sudah bersuami, tetapi suka bermain serong dengan lakilaki lain. Hal yang menarik lagi, dari tokoh "saya", diketahui bahwa Si Kepala Anjing juga, dapat dikatakan, memiliki orientasi heteroseksual. Orientasi heteroseksual Si Kepala Anjing diketahui ketika tokoh "saya" mengakui bahwa kemaluan dirinya pernah diendus oleh Si Kepala Anjing (Ayu, 2012, hlm. 7).

Lain hal dalam cerita pendek "Lintah". Tokoh "saya" menghadirkan sosok perempuan (ibu) yang memiliki "piaraan" yang disebutkan sebagai lintah. Tokoh ibu selalu menomorsatukan piaraan dibandingkan tokoh "saya" yang berposisi sebagai anak. Tokoh ibu sangat suka dengan segala aktivitas seksual bersama "lintah". Dari situasi tersebut, tokoh "saya" tampak tidak mampu melakukan pergerakan melawan wacana dominasi, yang tidak hanya muncul dari patriartki, melainkan hadir dari keberadaan sosok ibu (perempuan).

Selanjutnya, dalam cerita pendek "Wong Asu", tokoh "saya" yang tidak diketahui status gendernya, menjadi "mata" untuk menyaksikan keberadaan laki-laki (Wong Asu) yang mendapatkan opresi wacana dominan yang bermuara dari orang tua. Wong Asu tidak kuasa terhadap keinginan orang tua yang memaksa agar Wong Asu bersetubuh dengan pasir hingga menjadi klimaks. Dari penarasian yang dilakukan oleh tokoh "saya" dapat dipahami keberadaan laki-laki yang tidak kuasa melawan wacana dominan sekelilingnya.

Selain menggunakan sudut pandang orang pertama ("saya"), sudut pandang orang ketiga juga digunakan dalam penarasian. Konsep sudut pandang orang ketiga berkaitan dengan keleluasaan mengenai kedalaman narator menyelami tokoh hingga ke dalam pikiran dan kedalaman yang berkaitan dengan sudut pandang yang didasarkan pada upaya narator menilai pikiran dan gagasan tokoh untuk membedah kesadaran tokoh (Todorov, 1985). Penggunaan sudut pandang orang ketiga tampak pada cerita pendek "Durian", "Melukis Jendela", dan "Namanya...". Melalui sudut pandang orang ketiga, pembaca ditarik mendekati tokoh secara detail terhadap segala hal yang menyangkut diri tokoh seperti perilaku, pemikiran, fisik, dan sebagainya.

Dalam cerita pendek "Durian", tokoh Hyza, seorang perempuan dengan tiga anak, yang tidak memiliki kekuasan menolak pengaruh dari imajinasinya (hasrat). Hasrat yang tidak dapat dilawan oleh tokoh Hyza adalah "durian" yang berasal dari alam mimpi. Tokoh Hyza ingin memiliki "durian" dan berusaha pula untuk tidak memakannya. Jika Hyza memakan "durian" dari alam mimpi tersebut, anak-anak Hyza akan menderita kusta. Hyza adalah korban dari hasrat yang melakukan hubungan seks hanya untuk mendapatkan "durian". Meskipun hanya menyimpan dan tidak memakannya, anak-anak Hyza tetap menderita kusta. Namun, dari situasi tersebut, melalui sudut pandang orang ketiga ini, alam pemikiran tokoh Hyza dapat tampak alasannya menginginkan "durian", sebagaimana terbaca pada kutipan berikut.

$\begin{array}{lcr}\text { "karena saya } & \text { manusia } & \text { yang } \\ \text { dikaruniai } & \text { rasa } & \text { untuk } \\ \text { menginginkan, } & \text { namun } & \text { saya }\end{array}$


dikaruniai akal untuk memutuskan apa yang tidak dan akan saya lakukan" (Ayu, 2012, hlm. 29).

Seperti halnya tokoh Hyza, tokoh Mayra dalam cerita pendek "Melukis Jendela", secara fisik, digambarkan sebagai perempuan cantik yang diturunkan dari kecantikan ibunya. Dari sudut narator, tokoh Mayra mengalami kekerasan seksual dari teman-temannya.

"Ia berkeluh kesah tentang teman-teman prianya di sekolah yang kerap meraba-raba payudara dan kemaluannya sehingga menyebabkan teror dalam dirinya setiap berangkat ke sekolah." (Ayu, 2012, hlm. 32).

Sementara itu, secara status sosial, Mayra berada pada strata atas dengan fasilitas lengkap.

“... seorang anak berayahkan penulis dan pengusaha terkenal, satu-satunya murid yang pulang dan pergi sekolah dengan mengen-darai mobil mewah dengan sopir pribadi, agar tidak seenaknya saja melihat mereka dengan sebelah mata." (Ayu, 2012, hlm. 39).

Bila Hyza dinarasikan sebagai perempuan yang menjadi korban kekerasan seksual, dalam cerita pendek "Namanya...", tokoh perempuan direpresentasikan oleh tokoh Memek dan Ibu. Nama Memek yang disematkan pada tokoh perempuan, anak dari Ibu dan Sumarno, memberikan beban psikologis bagi tokoh Memek, yaitu ambisius, pendendam, dan bermuka dua. Dari sudut pandang narator diketahui bahwa tokoh Memek tidak hanya menerima opresi dari lingkungan sekitarnya mengenai nama memek, melainkan juga menerima opresi dari Ibunya yang selalu mengungkit keberadaan bapak (laki-laki) yang tidak bertanggung jawab.

Berdasarkan uraian di atas, diketahui bahwa sudut pandang orang pertama tunggal "saya" dan orang ketiga memberikan wawasan mengenai posisi perempuan. Sudut pandang "saya" berkemungkinan memberikan pemahaman dari dalam mengenai konstruksi berpikir bahwa perempuan hadir sebagai subjek yang berdialektika terhadap wacana dominan (patriarki) yang melingkupi tokoh perempuan. Melalui sudut pandang ketiga, perempuan pada akhirnya dilihat secara berjarak dari diri luar subjek perempuan dan dari itulah posisi perempuan sebagai subjek tampak sebagai yang terdominasi oleh ruang patriarki.

\section{Pemosisian Perempuan}

Dari strategi penarasian perempuan diketahui bahwa tokoh-tokoh perempuan dalam cerpen berada pada posisi terdominasi oleh wacana dominan (patriarki). Hal selanjutnya yang akan dibahas adalah pergerakan (resistansi) tokoh-tokoh perempuan dalam menyikapi wacana dominan (patriarki). Hadirnya resistansi disebabkan oleh wacana dominan yang mencengkeram kuat posisi perempuan. Dalam cerita pendek "Mereka Bilang, Saya Monyet!" resistansi ditunjukkan oleh tokoh "saya" melalui beberapa hal. Pertama, tokoh "saya" melakukan adu argumen perihal kesamaan perempuan dan laki-laki. Tokoh "saya" tampak berdialektika dengan mempertanyakan fungsi otak laki-laki dalam menghadapi perempuan.

"Waktu saya menyatakan bahwa saya juga mempunyai hati, mereka tertawa dan memandang saya dengan penuh iba atas 
kebodohan saya. Katanya hati yang mereka maksudkan adalah perasaan, selain itu mereka juga mempunyai otak. Tapi ketika saya protes dan menyatakan bahwa saya pun punya otak, lagilagi mereka tertawa terbahakbahak. Katanya, otak yang mereka maksudkan adalah akal." (Ayu, 2012, hlm. 2).

Tokoh "saya" menyatakan bahwa perempuan (saya) juga memiliki hati dan otak dan berfungsi sama dengan otak dan hati laki-laki. "Waktu saya menyatakan", pada bagian inilah menjadi sebuah tanda resistansi terhadap pendapat laki-laki bahwa perempuan tidak memiliki otak dan hati. Melalui pernyataan itu, tokoh "saya" melakukan sebuah resistansi untuk mengubah mindset laki-laki dalam menganggap tokoh "saya" (perempuan).

Penyataan tokoh "saya" mengenai kepemilikan otak yang sama selanjutnya menjadi sarana untuk membuktikan bahwa otak tokoh "saya" berfungsi lebih baik dari otak laki-laki.

"Tiba-tiba saya terpanggil untuk iseng. Saya meminta selembar kertas dan meminjam pen dari pelayan. Saya mulai menulis di secarik kertas itu dan meremasnya di dalam tangan saya. Lalu saya mengedipkan mata ke arah laki-laki berkepala buaya di depan saya sambil mengisyaratkan untuk mengikuti saya ke kamar mandi. Si Kepala Buaya mengerti maksud saya dan menyeringai senang sambil menganggukkan kepala. Saya berjalan ke arah kamar mandi, sambil dengan diam-diam menyelipkan secarik kertas di balik kerah baju si perempuan berkepala ular.
Saya menunggu di dalam kamar mandi. Tidak lama pintu diketuk. Saya membuka pintu. Si Kepala Buaya menyeruak masuk dan memberondong saya dengan ciuman. Saya cekik lehernya dan saya sandarkan dia ke dinding. Saya hajar mukanya seperti apa yang saya harapkan sebelumnya. Pintu kamar mandi diketuk. Saya membuka pintu dan Si Kepala Ular sudah berdiri berkacak pinggang di depan pintu. Saya mempersilakan ia masuk dan meninggalkan mereka. Saya mendengar suara tamparan di pipi Si Kepala Buaya tempat saya menghajarnya tadi." (Ayu, 2012, hlm. 9).

Kutipan tersebut menjadi titik tolak pembuktian bahwa otak tokoh "saya" berfungsi lebih baik daripada otak Si Kepala Buaya (laki-laki) yang telah kalah dengan naluri (nafsu) seksualnya. Kecerdasan tokoh "saya" menunjukkan kepiawaian dalam menggunakan strategi perlawanan terhadap laki-laki. Ibaratnya, satu kali jurus menghasilkan dua pukulan telak yang menimpa lawan. Hal tersebut dilakukan oleh tokoh "saya" dalam menunjukkan resistansinya terhadap laki-laki.

Lain lagi dengan tokoh "saya" dalam cerita pendek "Lintah". Tokoh "saya" berada pada posisi liyan dihadapan Ibu yang disebabkan oleh kehadiran "lintah" (laki-laki). "Lintah" tidah hanya menghisap Ibu, melainkan juga menghisap tokoh "saya".

"Beberapa kali diri $r$ tanpa
membelah dinasil
sepengetahuan Ibu, lintah makin
menjadi-jadi. Ia membelah
dirinya menjadi tiga, empat,


bahkan lima. Dan kali ini sudah tidak lagi menyelinap dalam kantung saya. Ia menyelinap ke bawah baju saya. Yang satu menyelinap ke pinggang saya. Yang satu lagi ke perut saya. Dan mereka berputar-putar sesuka hati menjelajahi tubuh saya sambil mengisapi darah saya. Saya semakin membenci lintah. Dan saya mulai membenci Ibu." (Ayu, 2012, hlm. 15).

Kutipan tersebut menunjukkan bahwa tokoh "saya" juga menjadi korban dari "lintah" yang sebelumnya hanya menghisap Ibu. Situasi tersebut juga menjadi bukti ketidak mampuan tokoh "saya" yang sebelumnya telah melakukan resistansi terhadap "lintah". Menyemprotkan racun serangga menjadi satu-satunya wujud resistansi tokoh "saya" dalam cerita pendek "Lintah"

"Saya pernah mencoba pura-pura targanggu nyamuk dan menyemprotkan obat serangga ke seluruh ruangan dengan harapan racun serangga itu dapat membunuh lintah.” (Ayu, 2012, hlm. 13).

Tokoh Hyza dalam cerita pendek "Durian", yang bernuansa realismemagis, melakukan resistansi terhadap wacana yang hadir dari mimpi dengan hadirnya laki-laki dan "durian". "Durian" menjadi sebuah metafor dari kenikmatan yang ditawarkan oleh lakilaki. Tokoh Hyza mengalami resistansi internal dalam diri terhadap kenikmatan yang ditawarkan oleh laki-laki dalam mimpi. Tokoh Hyza mengalami dilema yang ditandai dengan berulang kalinya durian tersebut dibuang dan beberapa kali itu pula durian diambil untuk dibawa pulang. Hal lainnya adalah ketika tokoh Hyza tidak lagi merasa malu dalam hal melakukan hubungan seksual.

"Hyza bercinta dengan banyak laki-laki. Ia tidak pernah malumalu menyatakan keinginan seksualnya kepada siapa pun yang diinginkannya." (Ayu, 2012, hlm. 20).

"Ketika Stefan tertidur, Hyza mulai memerkosa Stefan. Ia mengunyah bibir Stefan, melucuti baju dan memuaskan kehendaknya di atas tubuh Stefan yang tetap pura-pura tertidur." (Ayu, 2012, hlm. 21).

Kutipan pertama, tokoh Hyza menunjukkan tindakan aktif dalam memulai hubungan seksual, yaitu ia tidak pernah malu-malu menyatakan keinginan seksualnya. Tokoh Hyza menunjukkan pembalikan wacana umum yang menganggap bahwa perempuan pasif dalam hal memulai sebuah hubungan seks. Selain itu, tokoh Hyza juga menunjukkan bahwa dirinya (perempuan) juga memiliki hasrat seks yang sama dengan laki-laki dan sudah sewajarnya bahwa dirinya (perempuan) juga berhak memulai terlebih dahulu dalam hubungan seks. Hal serupa juga ditunjukkan dalam kutipan kedua. Tokoh Hyza memperkosa Stefan (laki-laki). Dalam wacana umum, pemerkosaan (secara seksual) biasanya dilakukan oleh laki-laki terhadap perempuan. Sementara itu, seolah ingin membalikkan wacana umum, Hyza melakukan tindakan aktif memerkosa (memperdayai secara seksual) terhadap Stefan (laki-laki).

Resistansi lainnya adalah yang dilakukan oleh tokoh Mayra dalam cerita pendek "Melukis Jendela". Seperti halnya cerita pendek "Durian", cerita pendek Melukis Jendela juga bernuansa realisme-magis. Resistansi tokoh Mayra 
muncul sebagai bentuk opresi seksual yang dilakukan oleh teman-teman prianya dengan meraba payudara dan kemaluan (Ayu, 2012). Resistansi pertama yang dilakukan oleh tokoh Hyza adalah dengan melakukan kekerasan fisik terhadap salah satu teman prianya (Ayu, 2012). Opresi seksual yang menimpa tokoh Mayra karena, salah satunya, berwajah cantik yang turun dari kecantikan ibunya. Tokoh Mayra menyadari bahwa kecantikan adalah sumber malapetaka bagi dirinya sehingga sering mendapatkan kekerasan seksual dari teman-temannya. Dari pemikiran tersebut, tokoh Mayra menyayat wajahnya.

"Ibu, apakah Ibu secantik yang mereka katakan Dan mengapa hanya kecantikan itu saja yang Ibu wariskan? Saya ingin Ibu. Saya tidak ingin kecantikan ini?"

Lamat-lamat ia merasakan tangan Ibu berhenti mengelus rambutnya. Ibu berjalan menuntunnya ke dapur dan memberinya sebilah pisau.

"Sayat wajahmu, Nak...." ....

Perlahan Mayra menyayat pipinya. Ia tersenyum." (Ayu, 2012, hlm. 34).

Pipi sebagai salah satu simbol kecantikan perempuan yang biasa bersanding dengan ungkapan "rona merah pipi" dalam resistansi yang dilakukan oleh Mayra menjadi sebuah tindakan ekstrem yang mencoba meruntuhkan hasrat laki-laki terhadap perempuan. Apakah laki-laki masih berhasrat terhadap perempuan jika tidak lagi cantik? Penolakan pertama terhadap resistansi yang dilakukan tokoh Mayra adalah dari ayahnya (laki-laki) yang merasa malu dengan keadaan tokoh Mayra.
Resistansi secara ekstrim selanjutnya yang dilakukan oleh tokoh Mayra adalah pemotongan penis milik Anton dan teman-teman yang telah melakukan hubungan seks dengan Mayra.

"Mayra mengenakan kembali baju seragamnya hingga darah di tangannya menempel pada seragam sekolahnya. Sebelum Mayra pergi, ia melirik sepintas ke arah Anton yang telentang di lantai kamar mandi tanpa penis lagi." (Ayu, 2012, hlm. 40).

Bagi laki-laki, penis menjadi bagian vital simbol kemampuan dalam seksualitas. Tanpa penis, keberadaan dan kejantanan laki-laki tidak bermakna dan tidak mampu menghadirkan (ke)kuasa(an) atas dirinya. Penghilangan alat vital laki-laki menjadi sebuah counter keras terhadap anggapan bahwa keirian perempuan terhadap laki-laki karena perempuan tidak memiliki penis (penis envy). Pemotongan penis yang dilakukan oleh Mayra menjadi simbolisasi bahwa perempuan juga memiliki kuasa atas laki-laki, sekaligus menghadirkan otoritas pribadi yang utuh dalam bertindak.

Seturut dengan tindakan Mayra, dalam cerita pendek "Wong Asu", tokoh "saya" melakukan tindakan sadis terhadap Wong Asu dengan membunuh dan memotong-motong tubuhnya yang kemudian diberikan kepada anjinganjing kampung. Tokoh "saya" melakukan pembunuhan terhadap Wong Asu dipicu oleh tindakan Wong Asu yang cenderung menyerupai perilaku asu (anjing).

Pemosisian tokoh "saya" dan Wong Asu dalam "Wong Asu" menghadirkan sebuah ruang dialektika untuk memaknai narasi dalam "Wong Asu". Jika tokoh "saya" dianggap 
perempuan, maka Wong Asu dapat juga diposisikan sebagai laki-laki, atau sebaliknya. Atau, tokoh "saya" dan Wong Asu sejatinya perempuan. Atau, bisa juga tokoh "saya" dan Wong Asu bergender laki-laki. Pemaknaan seperti uraian di atas akan sangat mungkin hadir dari perspektif yang berbeda.

Dalam kesempatan ini, tokoh "saya" dan Wong Asu diposisikan sebagai subjek tunggal, tokoh "saya" ialah Wong Asu dan Wong Asu ialah "saya". Jika tokoh "saya" membunuh Wong Asu, maka sejatinya tindakan membunuh tidak benar-benar meniadakan wadag Wong Asu karena Wong Asu sendiri merupakan alam pikir dalam diri tokoh "saya". Wong Asu sebagai alam pikir dalam diri tokoh "saya" dapat dimaknai melalui kutipan berikut.

- Ya, Wong Asu, begitulah ia dinamakan.

+Apakah kepalanya serupa anjing, berekor dan berkaki empat?

- Itu benar-benar anjing, namanya. Tidak, ia manusia biasa seperti kita. Hanya saja

+Hanya saja apa?

- Ia berkelakuan seperti anjing.

+Tunggu dulu, tadi kamu katakan ia dinamakan Wong Asu. Maksudmu setelah ia berkelakuan bagai anjing, atau memang sejak lahir?

- Sejak lahir.

+Sejak lahir dan selanjutnya ia berkelakuan seperti anjing. Apakah orangtuanya cenayang?

- Oh... tidak. Tapi saya yakin peran orantuanya sengat besar dalam pembentukan karakternya.
+ Berarti ia sudah dipersiapkan menjadi manusia anjing, begitu maksudmu?

- Mungkin juga tidak.

+ Lantas?

- Mungkin orangtuanya anjing! (Ayu, 2012, hlm. 77-78).

Melalui kutipan di atas dapat dimaknai bahwa Wong Asu tidak benarbenar berwujud dalam arti subjek fisik orang berkepala anjing. Wong Asu lebih mencerminkan pola pola pikir hereditas yang dibawa sejak lahir, yaitu manusia yang berperilaku layaknya anjing. Membunuh Wong Asu dapat dimaknai sebagai tindakan membunuh sifat-sifat anjing dalam diri tokoh "saya".

Dalam pemaknaan lainnya, belakangan, Wong Asu dinarasikan sebagai subjek laki-laki. Narasi tersebut terurai ketika "saya" mengisahkan sebab Wong Asu selalu melolong Wong Asu melolong dipicu pengalaman masa kecil ketika dipaksa oleh orangtuanya untuk menindih pasir yang dilubangi hingga mengalami orgasme. Tokoh "saya" menganggap lolongan Wong Asu sebagai kenikmatan yang pedih. Dari uraian tersebut, relasi Wong Asu dengan orangtunya memunculkan kemungkinan bahwa sifat-sifat yang dimiliki oleh Wong Asu tidak jauh berbeda dengan pola pikir orangtuanya. Kemungkinan itu dapat terjadi karena orangtua Wong Asu memiliki pengalaman batin yang sama semasa kecil, tetapi dengan cara yang berbeda. Dari keterangan tersebut dapat dipahami bahwa pola pikir dan perilaku orangtua Wong Asu turun pada Wong Asu sendiri.

Sealur dengan kejelasan gender Wong Asu, tokoh "saya" berikutnya dinarasikan sebagai subjek bergender perempuan. Tokoh "saya" dinarasikan sebagai perempuan ketika tokoh "saya" mengisahkan dirinya menuliskan cerita persetubuhan dengan ayahnya. Dari 
narasi tersebut hadir sebuah relasi antara Wong Asu dan tokoh "saya", yaitu tokoh "saya" menjadi teman Wong Asu sehingga tokoh "saya" mampu mengisahkan pengalaman bercinta serupa dengan Wong Asu yang pernah bercinta dengan ibunya. Kedekatan dengan tokoh "saya" dengan Wong Asu terjadi karena tokoh "saya" turut melolong dan menggongg serupa dengan Wong Asu. Melalui relasi tersebut tampak bahwa Wong Asu (laki-laki) mampu memberikan pengaruh kepada tokoh "saya" perempuan. Tokoh "saya" pada akhirnya turut berperilaku dan berpola pikir serupa dengan Wong Asu, seperti melolong dan menggonggong.

Berdasarkan perelasian tersebut dan dengan menariknya ke dalam perspektif pemosisian perempuan, tindakan membunuh Wong Asu pada akhirnya menempatkan tokoh "saya" sebagai subjek yang mencoba memutuskan rantai hereditas perilaku dan watak kebinatangan yang diturunkan oleh Wong Asu (laki-laki). Tokoh "saya" mampu menjadi pemegang kendali dan menjadi subjek utuh, tanpa menjadi Wong Asu, dengan cara menghilangkan sifat kebinatangan (anjing) melalui memutus rantai hereditas sifat kebinatangan dari Wong Asu.

\section{Satire Mereka Bilang, Saya Monyet! dan Djenar Maesa Ayu}

Dari penarasian dan resistansi yang dilakukan oleh tokoh-tokoh perempuan, hal yang tampak menarik dari strategi penarasian dengan menggunakan sudut pandang orang pertama dengan tokoh "saya" dan orang ketiga adalah hadirnya subjek laki-laki di mata tokoh "saya" (perempuan), tokoh Hyza, dan Mayra. Kehadiran sosok laki-laki dalam cerita pendek "Mereka Bilang, Saya Monyet!", "Lintah", "Durian", "Melukis Jendela",
"Wong Asu", dan "Namanya..." memunculkan anggapan bahwa Djenar Maesa Ayu berwacana dalam ruang diskursif dominasi patriartik, yaitu dalam bentuk sindiran keras terhadap laki-laki.

Satire yang muncul berupa penamaan laki-laki dengan nama-nama binatang. Nama-nama binatang yang melekat pada tokoh laki-laki, antara lain laki-laki berkepala buaya dan berekor kelanjengking, Si Kepala Gajah, Si Kepala Harimau, Si Kepala Serigala, Si Kepala Babi, Si Kepala Kuda, dan Si Kepala Sapi (cerpen "Mereka Bilang, Saya Monyet!"), laki-laki lintah (cerpen "Lintah"), dan Wong Asu (cerpen "Wong Asu"). Pemberian nama ini menjadi bentuk wacana yang diciptakan oleh Djenar Maesa Ayu untuk menghadirkan pengetahuan tertentu.

Pemberian nama tokoh laki-laki dengan nama binatang menjadi sebuah usaha untuk menyamakan sifat laki-laki dengan nama-nama binatang yang disematkan. Misalnya, Si Kepala Gajah. Meskipun binatang gajah adalah binatang yang sangat cerdas dibandingkan binatang mamalia umumnya jika sudah jinak, gajah jantan liar menghabiskan masa hidupnya untuk hidup sendiri. Laki-laki lintah identik dengan hewan lintah yang mengisap darah dan tidak akan berhenti mengisap jika belum benar-benar kenyang. Si Kepala Babi yang berelasi dengan hewan babi yang pemakan segalanya.

Pemberian nama-nama binatang terhadap laki-laki menjadi sebuah sindiran yang "menohok" jika jenis binatang itu semua dibandingkan dengan monyet (kera) yang dalam wacana umum memiliki struktur berpikir sama dengan makhluk yang dinamakan manusia. Di sini, Djenar Maesa Ayu memiliki kekuasan memproduksi wacana yang sealur dengan pendapat bahwa kekuasaan dapat ditemukan di mana-mana, dalam segala ruang 
interaksi, dan hampir mirip dengan metafisika-kekuasaan merembes dari bawah dan diciptakan setiap saat (Sarup, 2003). Setidaknya, jika berlandaskan pada teori evolusi Darwin, maka binatang yang mendekati perilaku manusia adalah monyet (kera). Ditarik dan direlasikan dengan judul antologi cerpen Mereka Bilang, Saya Monyet!, maka terdapat kemungkinan bahwa Djenar Maesa Ayu sedang melakukan pembalikan makna dari ungkapan tersebut. Jika Mereka adalah laki-laki yang disimbolkan dengan nama-nama binatang, berikut sifat-sifat binatang yang menyertai laki-laki tersebut, maka sebenarnya saya yang dibilang (dikatakan) sebagai monyet adalah lebih dekat dengan sifat-sifat manusia. Jadi, saya mendekati kepada sifat-sifat manusia yang lengkap dengan kesadaran dan akal, sementara itu mereka (lakilaki) yang memanggil saya monyet tidaklah lebih dari binatang-binatang selain monyet (kera). Di sinilah Djenar Maesa Ayu melakukan dekonstruksi makna melalui strategi dan penarasian perempuan untuk memaknai seluruh karya yang terangkum dalam antologi Mereka Bilang, Saya Monyet!.

\section{SIMPULAN}

Analisis yang telah diraraikan di atas menunjukkan bahwa cerita pendek "Mereka Bilang, Saya Monyet!", "Lintah", "Durian", "Melukis Jendela", "Wong Asu", dan "Namanya..." menggambarkan perempuan dengan menggunakan sudut pandang orang pertama dengan tokoh "saya" dan sudut pandang orang ketiga yang mengarahkan perhatian penuh terhadap tokoh Hyza dan Mayra mendudukan posisi perempuan sebagai sentral subjek dalam cerita pendek. Kedua, resistansi yang dilakukan oleh tokoh "saya", Hyza, dan Mayra yang berupa tindakan fisik dengan menyayat pipi, mengatur strategi perlawanan, dan pemotongan penis, merupakan respon terhadap wacana dominan patriarki. Ketiga, wacana dalam antologi cerita pendek Mereka Bilang, Saya Monyet! mengungkapkan sindiran (satire) kepada laki-laki melalui pemberian nama-nama binatang bahwa mereka (laki-laki) tidak lebih dari binatang berkaki empat dengan sifatnya masing-masing. Sudut pandang "saya" (monyet) membawa pemahaman bahwa "mereka" (laki-laki) yang mengatakan "saya" adalah monyet, sejatinya tidak lebih dari binatang-binatang berkaki empat yang memiliki sifat jauh di bawah monyet. Dari sinilah kemudian tampak bahwa cerita pendek dalam antologi Mereka Bilang, Saya monyet! sedang berdialektika dan menunjukkan resistansinya terhadap dominasi patriarki dengan cara memberikan nama hewan pada setiap laki-laki. Dari itulah kemudian tampak bahwa perempuan menempati subjek yang sedang berdialektika bergerak membebaskan diri dari opresi laki-laki melalui dialektika wacana bahwa mereka yang mengatakan saya monyet sejatinya tidak lebih dari anjing, gajah, dan sapi.

\section{DAFTAR PUSTAKA}

Ayu, D. M. (2012). Mereka bilang, saya monyet!. Jakarta: PT. Kompas Gramedia.

Bandel, K. (2006). Sastra, perempuan, seks. Yogyakarta: Jalasutra.

Brooks, A. (1997). Postfeminism: Feminism, cultural theory and cultural forms (edisi pertama). New York: Routledge.

Prasetyo, K. B. (2010). Membaca diskursus post-feminisme melalui novel "Perempuan di Titik Nol." Jurnal Komunitas, 2(2), 135-142. Diperoleh dari www.jstor. org/stable/42855181 
Ramazanoglu, C. (1993). Dezabilzing theory: Contemporary feminist debates by Michèle Barret and Anne Philips. Sociology, 27(2), 314-315. Diperoleh dari www.jstor.org/stable/42855181

Salam, A. (2018). Persilangan subjek posfemenisme:

Mencari perempuan kontekstual Indonesia. Makalah dalam Forum Mbulaksumur \#8 (Rabu, 16 Mei 2018) di Pusat Studi Kebudayaan, Universitas Gadjah Mada, Yogyakarta.

Sarup, M. (2003). Post-strukturalism and posmodernism: Sebuah pengantar kritis (edisi pertama). (Y. Martanto, Ed.). Yogyakarta: Jendela.

Setyowati, R. (15 Mei 2017). Djenar Maesa Ayu: Saya bukan feminis. Diperoleh dari https://www.saluransebelas.com/ djenar-maesa-ayu-sayabukanfeminis/.

Sukma, M. (2011). Representasi kekerasan seksual terhadap perempuan dalam kumpulan cerita pendek Mereka bilang saya monyet karya Djenar Maesa Ayu. Skripsi. Fakultas Bahasa dan Seni, Universitas Negeri Yogyakarta.
Todorov, T. (1985). Tata sastra (edisi pertama). (O. K. S. Zaimar, Editor.). Jakarta: Djambatan.

Weedon, C. (1993). Feminist Practice and Poststructuralist theory. constructive feminism (4th ed.). Oxford: Blackwell Publisher. DOI: 10.7591/cornell/9780801453199. 003.0002

Wildan. (2014). Resistensi dan model kesetaraan gender dalam novel Perempuan berkalung sorban karya Abidah El Khalieqy. Kandai, 10(2), 216-230. DOI: 10.26499/jk.v10i2.324

Wiyatmi. (2006). Fenomena seks dalam novel indonesia mutakhir karya pengarang perempuan: Kajian kritik sastra feminis. Humaniora, 18(3), 213-225. doi: 10.22146/jh.v18i3.877

. (2010). Citra perlawanan simbolis terhadap hegemoni patriarki melalui pendidikan dan peran perempuan di arena publik dalam novel-novel Indonesia. Atavisme, 13(2), 243-256. 